\title{
El guionista chileno: análisis cuantitativo sobre el oficio de escribir para cine
}

\author{
The Chilean screenwriter: Quantitative analysis on the craft \\ of writing for film
}

\author{
0 roteirista chileno: análise quantitativa do trabalho de escrever \\ para o cinema
}

RUBÉN DITTUS, Universidad Central de Chile, Santiago, Chile (ruben.dittus@ucentral.cl)

\section{RESUMEN}

El estudio describe la metodología empleada para construir el guion en el cine chileno de la última década. Los resultados provienen de cuestionarios aplicados a más de sesenta realizadores (guionistas, directores y productores), y constatan la existencia de orientaciones o formas de trabajo para la escritura en las etapas de preproducción y edición, advirtiéndose la convivencia de diversos procesos creativos en quienes confeccionan el escrito, tanto en la generación de la idea dramática como en la composición. Los caminos son tan variados como realizadores existen; así, el guion parece ser visto más como una metodología que como un texto acabado.

Palabras clave: guion; cine; análisis cuantitativo; industria audiovisual; Chile.

\section{ABSTRACT}

The study describes the methodology used to construct the script in the Chilean cinema of the last decade. The results come from questionnaires applied to more than sixty filmmakers (screenwriters, directors and producers), and confirm the existence of guidelines or ways of working for writing in the stages of preproduction and editing, noting the coexistence of various creative processes in those involved in the writing, both in the generation of the dramatic idea and in composition. The paths are as varied as filmmakers exist; thus, the script seems to be seen more as a methodology than as a finished text.

Keywords: script; cinema; quantitative analysis; audiovisual industry; Chile.

\section{RESUMO}

O estudo descreve a metodologia utilizada para a escritura de roteiro no cinema chileno da última década. Os resultados provêm de questionários aplicados a mais de sessenta cineastas (roteiristas, diretores e produtores) e observam a existência de orientações ou formas de trabalho para a escrita nas etapas de pré- produção e edição, observando a coexistência de vários processos criativos que influenciam a escrita, tanto na geração da ideia dramática como na composição. Os caminhos são tão variados quanto o número de cineastas; Assim, o script parece ser visto mais como uma metodologia do que como um texto acabado.

Palavras-chave: roteiro; cinema; análise quantitativa; indústria audiovisual; Chile.

Forma de citar:

Dittus, R. [2017). El guionista chileno: análisis cuantitativo sobre el oficio de escribir para cine. Cuadernos.info, [41], 193-207. https://doi.org/10.7764/cdi.41.1139 


\section{INTRODUCCIÓN}

Este trabajo se enmarca en una investigación más amplia, cuyo objetivo general era describir la metodología empleada por los guionistas y realizadores chilenos en las películas de ficción estrenadas entre 2003 y 2013. Específicamente, se buscó describir los núcleos narrativos y principios básicos de la dramaturgia que se privilegian en el trabajo de creación de guiones en el cine chileno. El diseño metodológico abordó esos objetivos a partir de dos tipos de instrumentos: cualitativos y cuantitativos. Al primer grupo pertenecen aquellas técnicas de análisis narratológico aplicadas a las estructuras narrativas. Para ello, se elaboró un modelo de análisis fílmico que permitió deconstruir el ensamblaje de la estructura narrativa del texto audiovisual y describir las estructuras subyacentes y las temáticas recurrentes en las historias contadas. El resultado de ese análisis ha sido presentado en otras instancias académicas (Dittus, 2015b; 2016). Al mismo grupo pertenece el conjunto de entrevistas aplicadas a 33 agentes de la industria audiovisual chilena-directores, guionistas, dirigentes gremiales, encargados de reparticiones gubernamentales vinculadas a la promoción del cine chileno, investigadores y críticos audiovisuales-. El análisis de esos resultados permitió observar la percepción que los guionistas tienen de sí mismos, discutir sobre temas que luego aparecen como relevantes para creación de historias, intercambiar información sobre el contexto institucional de la profesión, así como respecto de las oportunidades laborales y las fuentes de financiamiento. De hecho, esos datos fueron clave para configurar una serie de categorías específicas que definen al guion no como un texto acabado, sino como un conjunto de etapas y mecanismos de escritura, filmación y edición. Esto significó entender el guion como una metodología, es decir, un proceso de reescritura que termina en la sala de montaje. Otros trabajos (Basulto, 2016; Dittus, 2017) han dado cuenta de esas experiencias investigativas.

En este artículo se presentan el instrumento cuantitativo y su análisis. Para sistematizar y presentar en cifras las opiniones de quienes trabajan profesionalmente el cine en Chile, se aplicaron cuestionarios a más de sesenta realizadores. La tarea no era fácil, pues buscaba comprender la opinión que los guionistas y realizadores tienen de su actividad, y que, por lo mismo, revelaran la trama cotidiana que supone uno de los oficios más anónimos en nuestro país. En esa línea, se confiesa abiertamente el discurso identitario de una actividad en la que se ventilan formas de relación con los actores y el equipo de dirección. Se partió de una hipótesis que se fue confirmando mientras se avanzaba en el estudio: el guion en Chile se aleja del clásico formato que se enseña en los talleres y manuales de guion en Occidente. Desordenadas anotaciones, esquemas, archivadores, breves escritos son, en general, los textos con los que se encontrará un coleccionista de estas historias. Este rasgo es importante, ya que en gran medida da cuenta de actos políticos explícitos. Un director que se aleja de las precisiones narrativas previas abraza uno de los atributos menos discutidos del hacer cine: el enjuiciamiento al realismo y el deseo de soltar amarras con el capitalismo audiovisual.

Lo anterior alimenta la tesis de que el cine no es fácil de explorar. En él descansan visiones discursivas y de mercado que cruzan cualquier aspiración artística. La mayoría de las veces el público es menos receptivo que la crítica o que el jurado en festivales especializados. Por esa razón, nos preguntamos sobre el trabajo escritural que hay detrás de cada película chilena estrenada. ¿Hay estándares profesionales de escritura en el cine chileno? ¿Qué modelos de creación para el cine de ficción se han desarrollado durante la última década? ¿Qué principios dramatúrgicos han asumido los guionistas para su aplicación en el proceso de escritura creativa? Esta reflexión obliga a indagar sobre cuestiones creativas y metodológicas en uno de los productos menos estudiados de la industria audiovisual

Los resultados generados por el cuestionario son relevantes en dos aspectos: documentan el interés que existe entre los realizadores por conocer temas vinculados a su desempeño profesional y confirman un conjunto de prácticas no institucionalizadas que impiden hablar - a juicio de la mayoría de los encuestados- de una industria audiovisual.

\section{ANTECEDENTES}

Los antecedentes teóricos del estudio se anclan en la tesis de que el cine no se entiende alejado de un modelo de desarrollo. Dicho de otra manera, nadie hace cine "en el aire". El caso chileno, como cualquier otro, tiene sus particularidades. El modelo cultural neoliberal se ha transformado en el nuevo referente sociocultural del cine chileno. Como indica Trejo (2014, p. 25), eso se expresaría tanto en los recursos dramáticos, visuales y estéticos como en la psicología, las motivaciones y las vinculaciones sociales de los personajes, donde la realización narcisista del yo es más importante que la trama del "vivir juntos". Obviamente, ese modelo 
también repercute en la creación del guion y su metodología (donde se justifica la libertad del creador en el negocio del cine), un lugar en donde el mercado se expresa en tanto forma y fondo, como lugar de adhesión o rechazo. Precisamente, en la búsqueda de propuestas autorales periféricas y de nuevas políticas de subjetividad (Póo, Stange, \& Salinas, 2012), las preguntas buscaban indagar, además, sobre esos "otros métodos de trabajo escritural" o de productos audiovisuales que se insertan en lo que Urrutia (2013) denomina el "carácter centrífugo del cine chileno", más subjetivo, descentrado y con apropiaciones discursivas alejadas del modelo narrativo más clásico.

No se debe olvidar que, en las universidades norteamericanas, el guion en Occidente-como disciplina o técnica- se estudia partiendo de la época del cine mudo. A pesar de ese paralelismo, cuando se empezó a escribir sobre teoría del cine, esa producción intelectual se distinguió desde un inicio de la teoría del guion (Dittus, 2015a). La falta de teorización contrasta con un conjunto de normas que hablan de la eficacia de las estructuras, especialmente diseñadas para los narradores audiovisuales de hoy. El resultado es categórico: aunque la creatividad no pueda aprenderse, hay un destacado número de manuales que enseñan técnicas o estilos del guion. En lo que respecta a los modelos narrativos que sirven de guía o inspiración para quienes ejercen el oficio de escribir para cine, hay que ser precisos. Como se indicó en otro trabajo que fundamenta la necesidad de investigar el guion en Chile (Dittus, 2015a), la mayoría de los manuales de guion de reciente publicación o edición postula estructuras narrativas, paradigmas creativos y recursos estilísticos de diversa índole. Sin embargo, su análisis no dice mucho sobre el impacto en los cursos formales de guionismo. Si bien se trata de parámetros de escritura audiovisual cada vez más extendidos en las escuelas de guion en el mundo-y que Hollywood llama "fórmulas de éxito" (Tubau, 2011)- no hay información suficiente para declararlos como relevantes en el proceso creativo chileno. Es en ese escenario académico donde los textos de Syd Field (1979), Linda Seger (2002), Robert McKee (2002), Christopher Vogler (1998) o Black Snyder (2010) son de lectura obligatoria en otras partes de América y el mundo. Se han convertido en algo más que recomendaciones. Se trata de verdaderos tratados o fórmulas dogmáticas que enseñan sobre el riesgo, el nudo dramático o la transformación de los personajes. Como dice Tubau, "el dominio casi absoluto del cine de Hollywood desde mediados de los años ochenta y la particular manera en la que obtenía sus mayores ingresos, favoreció la adopción de técnicas narrativas que pudieran lograr el éxito rápido, lo que se ha llamado blockbusters, que hacen que millones de personas en todo el mundo llenen miles de salas, al menos durante el primer fin de semana" (Tubau, 2011, p. 20). No es casualidad, entonces, que se reconozca a Aristóteles como el más antiguo maestro de los guionistas modernos.

Con más de dos mil años de antigüedad, la Poética es la primera gran obra de estructura dramática que se conoce. Allí, los principios de la trama y los tres actos garantizan la cohesión y la unidad discursiva de la obra, considerada como un todo (Aristóteles, 2003). La Poética, considerada como un saber acerca del arte en relación a la producción de las cosas, es un saber de carácter normativo, y se ocupa principalmente de la estética de la tragedia. Las normas que allí se definen tienden a que el texto dramático (cualquiera sea su lenguaje: teatro, cine, televisión o medios digitales) resuma en una propuesta específica las condiciones peculiares de la belleza. El cine adopta cada uno de esos principios inspiradores, ordenando la línea argumental y las acotaciones del texto en un conjunto de recursos dramatúrgicos (Cano, 1999) mediante los cuales el autor se imagina la puesta en escena. Un estudio llevado a cabo por Brenes (2014) indica que entre 2007 y 2012 se registraron más de cien nuevos libros sobre guion en la Biblioteca del Congreso de los Estados Unidos. De ese listado, la mayoría aborda el texto de Aristóteles desde un enfoque didáctico y técnico, desaprovechando una segunda lectura de la obra: su dimensión filosófica y sapiencial y, por tanto, de mayor interés profesional para guionistas y espectadores. Al respecto, se dice que "cuando se refieren a cuestiones técnicas e interpretación la Poética solo es como un manual de consejos para la escritura, en algunos casos terminan rechazando las propuestas de Aristóteles por considerarlas rígidas, y en otros, reducen el alcance del texto" (Brenes, 2014, p. 66).

En otro estudio, la misma investigadora (Brenes, 2011) postula que la influencia de Aristóteles en los manuales de guion también se observa en la manera en que se diferencian la primera escritura de la reescritura. En la primera, el guionista se preocupa de la estructura de la trama y de los personajes, los diálogos y las acciones. En cambio, en la reescritura se busca descubrir la estructura poética profunda que da sentido a la historia. En otras palabras, en la obra de Aristóteles se reconocen los fundamentos de cómo contar 
una buena historia. A partir de esas estructuras, en la industria audiovisual actual se encuentran historias similares, con escasos ingredientes de originalidad. Todo se debe -según Daniel Tubau (2011) - a una mala interpretación de la obra de Aristóteles. Según el autor la verdadera teoría aristotélica de la narración es mucho más interesante: un guion debe ser como un organismo en el que todas las partes contribuyen a un mismo fin. Cumplir una función. Para Tubau, la forma estándar de escribir guiones es una interpretación formalista en grado extremo que no tiene nada que ver con los griegos. "No hay comparación posible entre la mesura de un Racine y el dolor sin remedio de un Sófocles, ni siquiera entre las burlas de un Molière y los excesos, groserías e insultos de un Aristófanes, que se parece más a Rabelais y su Gargantúa y Pantagruel que a quienes en la corte francesa pretendían legislar la literatura basándose en un supuesto modelo griego", dice Tubau (2011, p. 31).

Ese origen teatral explica la influencia dramatúrgica en los manuales y cursos formales de guion. No cabe duda de que el documento creativo más parecido al guion es el texto teatral. Existen similitudes respecto del orden de los diálogos, la presentación de las escenas y las acotaciones del autor para el equipo, director o actores. En sus inicios, ese vínculo fue aun mayor El cine era prácticamente la grabación de una obra de teatro, pues carecía de producción argumental y narrativa. Las expresiones escénicas, una cámara fija como simulación de los ojos de un espectador y los actores dramatizando frente a la cámara, eran elementos que hacían del cine y el teatro una pareja sin muchos matices. Ambos formatos están, en definitiva, en constante diálogo. Como dice Pérez, "muy tempranamente el cine recurre a la construcción de un universo simplificado tomando directamente del melodrama teatral: oposición de principios contrapuestos [deber/pasión, lealtad/ amor, odio/perdón], tipificación extrema y esquematismo de personajes y situaciones, etc." (Pérez, 2004, p. 574). En su evolución, sin embargo, el cine tuvo que alejarse forzosamente del teatro, pues ya comenzaba a tornarse un arte independiente. La falta de sonido, sin duda, es la muestra característica del cambio de modelo que sufrió el cine, pues debió centrar su narración únicamente en la imagen (Pérez, 2004, p. 574).

Todos estos antecedentes hacen del guion un documento escrito con exigencias como las de cualquier texto dramático. Y como tal, tiene una doble carga: de valor literario y técnico. Es decir, debe plantearse comunicar ideas a un público, pero sin dejar cerrado el paso para su enriquecimiento durante el proceso de producción y realización (Robino, 2015). Esta naturaleza dual le exige al guionista ser puente entre la idea y el producto audiovisual, en una actividad en la que el esfuerzo colectivo y colaborativo es la exigencia número uno. Allí, entonces, aparecen otras figuras en ese camino creativo. Como texto acabado y en desarrollo, el guion necesita de una mirada revisora, que acompañe y juzgue, que ordene o enriquezca la opinión que se tiene de la obra. El asesor o el jurado en festivales y concursos de cine evalúan esa estructura que alguna vez fue aprendida o replicada en el complejo mundo de la industria cinematográfica. De otro modo, no se contratarían consultores de guion o dramaturgos con esa especial capacidad para "acompañar" el proceso de escritura. Ese usual apego a un conjunto de herramientas técnicas alimenta al autor crítico interno que todo guionista lleva consigo. La búsqueda de una metodología que potencie el pensamiento narrativo audiovisual es la meta que los programas de formación en guion se proponen año tras año, con disímiles resultados. En ese contexto se validan términos como talento, creatividad, premisa, nudo dramático y fuerza antagónica.

El espectador es otro agente a considerar. Acostumbrado a finales felices o a giros dramáticos en el minuto setenta del tercer acto, muchas veces no evalúa bien una película que escapa a ese paradigma. Se trata de una especie de narrador omnisciente que descansa en el inconsciente del espectador, ya que conoce la trama, a los arquetípicos personajes y cuál será final de la historia. El mercado del cine en Chile no es inmune a esa tendencia. Lo paradójico es que, al parecer, los guionistas más rebeldes no están dispuestos a considerar a la audiencia, generando una especie de lucha con el espectador, algo así como "si no entiendes mi película, es tu problema". Esto se contradice con uno de los principios básicos de la teoría del guion, que es que la historia debe captar el interés de la audiencia, una norma que dio título a uno de los libros más leídos en el área: ¡Salva al gato!, de Black Snyder. En él, se indica que lo primero y principal es que al espectador le guste la persona con la que hará el viaje de hora y media: el personaje. "Yo lo llamo la escena de Salva al gato. Y no la incluyen en las películas. Y es fundamental. Es la escena en la que se presenta el héroe y le vemos hacer algo -como salvar un gato-, lo que define su personalidad y hace que a nosotros -los espectadores- nos caiga bien" (Snyder, 2010, p. 19). Para este autor estadounidense, el buen guionista tiene que pensar en todos y en cada uno de quienes intervienen en el proceso, 
incluido el director. Ese es el desafío para la construir la premisa de la película. El panorama chileno no tendría porqué ser diferente, a juicio de quienes desean profesionalizar una actividad que se mueve con una gran dosis de instinto y talento. Pareciera que un buen síntoma es que un gran número de guiones escritos no se filmen nunca (Sánchez-Escalonilla, 2001), aduciendo con ello selección y capacidad de producir las denominadas buenas historias.

Esta y otras problemáticas se han convertido en tema de reflexión. En Chile-así como en Europa-, donde las políticas de apoyo al cine y a los medios audiovisuales no obedecen a un modelo único (Gournay, 2004), las opiniones de guionistas y realizadores respecto de sus formas de trabajo han generado modelos alternativos que han repercutido con algo de ruido en las formas más tradicionales de hacer cine, aquellas que nos llegan por la distribución más comercial. El cineasta chileno Raúl Ruiz es quien mejor representa esa lucha anti-normativa. Contrario al aristotelismo hegemónico, Ruiz recuerda el primer enunciado de esa teoría: "Una historia se pone en marcha cuando alguien quiere algo y otro no quiere que lo obtenga. A partir de allí, a través de distintas digresiones, todos los elementos de la historia se ordenan alrededor de ese conflicto central" (Ruiz, 2013, p. 15). Ruiz propone multiplicar las formas narrativas, buscando aquellas que no se rijan por la fuerza centrípeta del conflicto central, que desea concentrar hasta el más mínimo detalle mediante un núcleo dramático que lo articula todo. Como acota Sánchez (2011, p. 109), con dicha metodología Ruiz va más allá, al filmar todo lo que está fuera del guion, tal como trabajan los músicos orientales, que tienen una partitura, para luego tocar todo, menos la propia partitura. Toda una desacralización del guion.

La alusión a Oriente no es antojadiza, pues se trata de una visión que tiene un concepto diferente del cosmos. A diferencia de la narrativa occidental, que necesita del choque violento entre dos opuestos a lo largo de tres o cinco actos para generar una historia, el Kishōtenketsu o arte de la narración contemplativa parte de la observación del universo, de entender cómo es y aceptarlo tal cual. Tiene su origen en la poesía china y coreana (y exportada a Japón), y cuenta con una estructura en cuatro actos en los que se narran dos eventos que en apariencia no tienen relación, pero la suma de ambos forma un todo que los trasciende (SanzMagallón, 2007). Los sucesos del primer, segundo y tercer acto no tienen que enfrentarse unos a otros. Pueden mantenerse separados. Aunque el cuarto acto unifica la obra, de ninguna manera implica violencia sobre los tres primeros, sino que solo extrae una conclusión de su yuxtaposición. Estas diferencias surgen, al parecer, por una obsesión humana por encontrar una estructura universal y "a una mala interpretación de la Poética de Aristóteles por varios expertos" (Tubau, 2015 , p. 88), que no es sino el resultado de una apresurada lectura del autor griego.

La historia del Chile reciente nos ha entregado algunas experiencias narrativas que se alejan de los paradigmas audiovisuales de Occidente, lo que es destacable pues comprueba que, muchas veces, el interés por hacer algo distinto surge en las mismas escuelas de cine y se diluye una vez que esos egresados se enfrentan a la realidad del mercado y las audiencias. Es lo que pasó con una generación de estudiantes de la Escuela de Artes de la Comunicación (EAC) de la Pontificia Universidad Católica de Chile, que funcionó entre 1970 y 1978. Como reconoce Vergara (2015, p. 118), "en el período de estudio, la energía audiovisual (de los estudiantes) estaba puesta en búsquedas formales y políticas, compartiendo ciertos rasgos con el cine latinoamericano de la época". Eran, en su mayoría, documentales militantes o ficciones comprometidas socialmente con una convergencia hacia lo real. Por un lado, el cine militante encontró espacios de exhibición en sedes de partidos políticos, asociaciones obreras y parroquias (Bolzoni, 1974), y por otro, un cine más experimental (u antropológico) se difundió en las salas de cine arte. Un grupo de esos futuros cineastas-liderado por Cristián Sánchez, uno de los realizadores más reconocidos hoy en día por su nítido trabajo autoral y de deconstrucción dramática-se interesó en las propuestas estéticas y narrativas de Raúl Ruiz, Luis Buñuel y Jean-Luc Godard. Se buscaba hacer un cine contrario a los cánones cinematográficos que se enseñaban en ese entonces. En palabras de Jorge Ruffinelli, "mientras por lo común, los cineastas niegan u ocultan con denuedo las huellas del cine anterior, a menudo bajo el ropaje neutralizador del realismo y del naturalismo, Sánchez enfatizó la condición constructiva, intelectual, experimental, de su cine, y la desarrolló sin timideces como relato fílmico de alta cualidad innovadora (...) buscó trabajar en la ambigüedad, en las pulsiones indefinidas del discurso fílmico, sin buscar la comodidad y el respaldo de lo establecido en la comunidad como forma, estilo y contenido" (Ruffinelli, 2007, p. 46). El nomadismo de Sánchez (así fue denominado su particular estilo arriesgado e incómodo) es un ejemplo de que otro cine es posible, desde formas y contenidos 
accidentados, innovadores y personales, pero con evidentes dificultades de lectura. Se trata de un desapego narrativo con lo clásico, que la industria audiovisual rara vez se permite. Las diferencias que se observan en los procesos creativos dibujan más bien un diálogo entre una especie de cine precario, rebelde y rupturista y otro cine más canónico y con paradigmas más industriales (Briceño, 2015).

Sin embargo, estos criterios alejados del modelo tradicional no se han sistematizado masivamente, estando acotados a experiencias audiovisuales que no son replicables en la academia formativa. De hecho, uno de los pocos manuales de guion escritos en Chile -Guion para un cine posible, de Orlando Lübbert- hace eco de aquellos recursos ya difundidos por los best sellers del guionismo. El autor y cineasta chileno reflexiona acerca de un cine posible, democrático y eficaz en la perspectiva latinoamericana, pero dando indicaciones sobre la construcción dramática, en la que los conceptos de punto de vista, idea cinematográfica y profundidad son valores supremos para la escritura audiovisual. En medio de dichas exigencias creativas, Lübbert pone el énfasis en el contexto - un cine con identidad-como el gran aliado del guionista, cuya gran riqueza la constituyen "historias inauditas, lugares alucinantes y personajes entrañables" (Lübbert, 2009, p. 13).

\section{METODOLOGÍA}

La confección del cuestionario consideró-además de los antecedentes teóricos- los datos recopilados en las entrevistas previas y de la documentación obtenida de algunos cursos formales de guion en Chile. La opinión de algunos coordinadores académicos fue relevante en esta etapa. En general, se describe que los cursos de guion y dramaturgia suelen volverse normativos, lo que a la larga resulta pernicioso para el oficio (Stranger, 2011). Esto se evidencia tras la convicción -para algunos- de que el manejo de una técnica podría dificultar las capacidades creativas de un escritor. Algunos entrevistados, en cambio, refuerzan la tesis de que la enseñanza formal permite liberar el imaginario y desarrollarlo plenamente. En este punto, varios consultados coinciden en que el estudio formal en escritura creativa "está muy en pañales" y que se privilegia una formación autodidacta.

En lo que respecta a la metodología creativa, es decir, a la manera en que los guionistas dan forma a la historia y sus argumentos filosóficos, las entrevistas dieron cuenta de tres corrientes: en primer lugar, guionistas que adscriben a un modelo clásico de construcción narrativa y que, además, se documentan e investigan sobre la temática a tratar; luego, aquellos que usan el guion como un puntapié inicial, desde el cual se inicia un proceso de improvisación, sobre la marcha, y que muchas veces termina concretándose en la sala de edición. Por último, los guionistas que recurren a sus vivencias personales para construir las historias que posteriormente se llevarán a la pantalla. En los dos últimos casos, se identifica la inclusión de elementos clásicos en su método, pero, por lo general, se constata que no es intencional. A la luz de las afirmaciones, pareciera que no existe una escuela de guion en Chile, y menos un modelo narrativo, como se observa en otros países de la región. La intuición es la mejor amiga de muchos realizadores, cuestión que se visibiliza, sobre todo, en óperas primas. Esta realidad tendría un arraigo histórico: los datos confirman que en Chile nunca ha habido una preocupación por el guion y, por mucho tiempo, se ha buscado algún modelo a seguir. La investigación académica tampoco ha mostrado interés en este ámbito, concentrándose más bien en revisiones históricas del cine chileno o su relación con la literatura y los medios de masas. Precisamente uno de esos estudios (Fuenzalida, Corro, \& Mujica, 2009) aborda el melodrama y lo melodramático en el cine y televisión chilenos de los años noventa, una serie de relatos marcados por el retorno a la democracia: temáticas que se expresan en una mirada socio-política desde el ámbito del mundo privado con dramas de personas comunes y corrientes.

Estas descripciones iniciales permitieron diseñar el instrumento, que buscó describir los principios básicos de la dramaturgia que se privilegian en el trabajo de creación de guiones.

De este modo, las variables medidas en el cuestionario fueron las siguientes:

a. Influencia teórica o filosófica en el proceso de escritura.

b. Injerencia de otro guionista, realizador o experto en la fase escritural.

c. Construcción del espectador modelo en el diseño narrativo.

d. Práctica del método recursivo en escritura.

e. La búsqueda de historias originales o adaptadas. 
f. La relevancia dada a la investigación o documentación.

g. Adhesión a algún modelo aprendido como fórmula.

El instrumento contenía 27 preguntas sobre el trabajo creativo para hacer cine en Chile, de las cuales la siguiente era abierta: con base en su experiencia en el área, ¿qué consejo daría a los nuevos realizadores (directores, productores y guionistas) que se inician en el cine chileno? El resto de las preguntas (26) eran cerradas y permitían marcar solo una de las cinco alternativas propuestas.

El cuestionario fue enviado por correo electrónico la semana del 2 de junio de 2015 a 170 guionistas, directores y realizadores chilenos que estrenaron algún producto audiovisual en la última década. Se incluyó en el mismo grupo a todos aquellos profesionales que, de algún u otro modo, participaron en el diseño narrativo de un largometraje de ficción. La documentación previa demostró que la tarea de guionista no está lo suficientemente diferenciada de la dirección de una película. La mayoría de las veces, los roles de director y escritor los ejerce una misma persona. Solo para efectos de registro, tanto el nombre como la actividad principal dan cuenta del rol específico de cada encuestado. Esos datos fueron usados para cifrar algunos fragmentos de respuestas. La base de datos fue cuidadosamente elaborada a partir de los portales web disponibles, repositorios de cine chileno, asociaciones gremiales, revistas especializadas y contactos personales. De los 170 envíos, 64 fueron respondidos en el plazo estipulado -antes del 22 de junio del mismo año-, y fueron procesados, tabulados y graficados en las semanas posteriores. Las estimaciones preliminares consideraban un tiempo aproximado de 15 minutos para responder las preguntas.

\section{RESULTADOS Y DISCUSIÓN}

El perfil de los realizadores encuestados indica que, en su mayoría, tienen menos de 50 años (44,4\% tiene entre 30 y 39 años de edad; $31,7 \%$ entre 40 y 49 años, y $17,5 \%$ entre 18 y 29 años) y que residen, mayoritariamente, en la Región Metropolitana (68,3\%); un porcentaje menor (6,3\%) indicó que reside fuera de Chile. Asimismo, un número considerable se autodefine como realizador profesional $(62,3 \%)$, seguido muy lejos por las opciones creativo $(13,1 \%)$ y artista $(11,5 \%)$.
Se trata, además, de realizadores cuyas preferencias de autoría o coautoría en el trabajo escritural no son lo suficientemente categóricas para hablar de una única metodología de creación. Ante la consulta ¿qué tipo de trabajos privilegió recientemente?, las respuestas no marcan tendencia: autoría sin asesor, con un 33,9\%; coautoría, con un $24,2 \%$; autoría con asesor, con un $22,6 \%$, seguido de autoría colectiva (trabajo creativo entre más de dos personas), con 19,4\%. En relación al tiempo dedicado a tareas de realización audiovisual, los encuestados dicen dedicar, en su mayoría (40,3\%) entre 4 y 8 horas diarias, seguido de un $24,2 \%$ de quienes dan entre 8 a 12 horas diarias al mismo trabajo. En cuanto a las actividades previas al rodaje o edición, una gran mayoría $(58,1 \%)$ afirma que ello demora más de tres meses.

Otro de los aspectos consultados en el estudio es sobre formación académica y cursos de especialización en escritura creativa. En general, se trata de un tema debatido y con aristas vinculadas a la libertad del realizador y a las influencias comerciales con las que se asocian los paradigmas más conocidos de la narrativa audiovisual, como el modelo de los tres actos, el viaje del héroe o la teoría del conflicto central. Los resultados indican que la teoría del guion está bastante presente en los encuestados, ya sea en cursos de universidades o institutos (29,5\%), talleres u otros cursos de formación $(26,2 \%)$ y la formación autodidacta $(32,8 \%)$. A pesar de dichas influencias, se reconoce que, al momento de diseñar los lineamientos de un relato, no se recurre con alguna preferencia teórica, pues ello varía según el proyecto audiovisual $(56,5 \%)$. Es un dato clave que el grupo consultado carezca de experiencia académica o en tareas de formación hacia otros realizadores. Cuando se les consulta sobre la última actividad asociada a la extensión o investigación en el área audiovisual, la mayoría indica la entrevista a un medio de comunicación (35\%), quedando más atrás las charlas (13,3\%), conferencias en una universidad o instituto $(18,3 \%)$ o ponencias en congresos o seminarios (11,7\%).

Lo anterior repercute en la existencia de algún anclaje teórico específico o en algún autor con mayor ascendiente en el proceso creativo. Solo una menor parte de los encuestados indica que al momento de iniciar la escritura o de diseñar los lineamientos de un relato audiovisual recurre a una idea original basada en su biografía o la de cercanos $(22,6 \%$ ) y a la teoría del conflicto central u otros modelos clásicos (12,9\%). La gran mayoría señala que varía según el proyecto audiovisual (56,6\%). En el mismo sentido, Aristóteles 


\begin{tabular}{lcc}
\multicolumn{1}{c}{ Alternativa } & Número de respuestas & Porcentaje [\%] \\
\hline Cursos de guion en universidad o instituto & 18 & 29,5 \\
\hline Master o diplomado de guion o escritura creativa & 6 & 9,8 \\
\hline Talleres o cursos de formación & 16 & 26,2 \\
\hline Lectura personal o formación autodidacta & 20 & 32,8 \\
\hline No he recibido clases formales de guion & 1 & 1,7
\end{tabular}

Tabla 1: PREGUNTA 6. Señale la última actualización de contenidos vinculados a teoría del guion que usted recibió

Fuente: Elaboración propia.

\begin{tabular}{lccc} 
& Alternativa & Número de respuestas & Porcentaje [\%] \\
\hline Aristóteles & 18 & 29,5 \\
\hline Joseph Campbell & 4 & 6,5 \\
\hline Syd Field & 6 & 9,2 \\
\hline Robert McKee & 17 & 27,4 \\
\hline Ninguno de los anteriores & 17 & 27,4 \\
\hline
\end{tabular}

Tabla 2: PREGUNTA 10. ¿A cuál de los siguientes autores o pensadores clásicos identifica como el de mayor influencia teórica para guionistas y estudiosos del guion en la actualidad?

Fuente: Elaboración propia.

y Robert McKee son los autores con mayor grado de identificación para guionistas (con 29\% y 27,4\%, respectivamente), pero compartiendo similar porcentaje con quienes optaron por la alternativa ninguno de los anteriores (27,4\%)

Estos datos parecen confirmar la ausencia o escasa relevancia asignada a la teoría del guion (o fundamentos de dramaturgia) en el currículo de los comunicadores audiovisuales. Una revisión inicial de los planes de estudio -que dio origen a otra investigación cualitativaindica que los cursos de guion están muy lejos de las horas asignadas a composición audiovisual o edición en las escuelas de cine en Chile. Esta constatación es, al menos, contradictoria, toda vez que la denominada generación de nativos digitales llega a la educación superior con conocimientos estéticos y audiovisuales muy superiores que su predecesora. Como dice una fuente consultada, "hoy en día los adolescentes nacen con las imágenes en la cabeza, son alfabetos digitales completos, pero de imágenes, entonces esa debe ser una herramienta que no debiera ser desconocida y a la cual debemos agregarle valor, pero debe ser una política de Estado" (profesor de guion, 44 años). A pesar de ello, para gran parte de los encuestados, el nivel actual del guion es superior en contenido y especialización. Hace un par de décadas, la ausencia de profesores de guion obligaba a los aprendices de cine a aprender haciendo. En la actualidad, esa formación se ha institucionalizado a través de las universidades, escuelas de cine y talleres de guion abiertos a la comunidad. Si a ello se suma la disponibilidad de libros técnicos, manuales de escritura y cursos en línea que enseñan la estructura del guion, se puede deducir que el interés en aprender sobre narrativa es cada vez más elevado, independientemente del camino que cada realizador trace.

En coherencia con estos resultados estadísticos, algunas opiniones refuerzan la necesidad de conocer bien los modelos narrativos para luego proponer 
otros caminos. La elección de estas opiniones es solo ejemplificadora. Un encuestado dice que es necesario:

Estudiar y comprender las bases del guion y el cine para después romperlas si se quiere. Pero teniéndolas realmente claras y entendidas. Incluso creo que se debería empezar escribiendo lo más clásico posible, intentando contar una buena historia, bien contada. También creo que adaptar obras literarias puede ser un gran aprendizaje en la construcción de historias, que clásicas o no, no es nada de fácil (director de cine, 34 años)

En una línea similar, otra opinión indica que se debe:

Estudiar y profundizar el conocimiento del tema, estudiar los personajes, luego definir qué es lo que se quiere comunicar, definir una estructura dramática de la historia, definir y conocer a los personajes, escribir el guion desde la historia y los personajes construidos, luego de este proceso y -con el guion escrito- buscar asesoría de un experto en guiones. El guion son los cimientos del edificio que luego será la película, si no funciona, la película tampoco lo hará. El proceso es largo (guionista, 38 años).

No cabe duda de que se le asigna un gran valor al guion, pero más como una base estructural que como un texto cerrado o inmodificable. Las preguntas referidas a esta materia confirman la hipótesis inicial de que, en general, quienes intervienen en los procesos de cambio al texto original son el director (con 70,5\% de las preferencias) y otros agentes del proceso de filmación (49,2\%).

Mención especial tiene la interrogante referida a la autoría del guion. En general, los manuales de escritura dan cuenta de la tensión que existe entre el trabajo autoral del guionista y las modificaciones o reparos que impone el director. Se constata, eso sí, que la realidad chilena dista bastante de esa polémica, ya que -mayoritariamente-el cine de nuestro país concentra ambos roles en la misma persona. A pesar de esto, se defiende la naturaleza del guion y sus posibilidades en todo el proceso de posproducción mediante el trabajo colectivo.

Algunas opiniones en esa línea son las siguientes:

En el guion, soñar. En el desarrollo de proyecto, pensar en la distribución. En la pre-producción, adaptar el guion al presupuesto. En rodaje, trabajar con guion técnico. En el montaje, que el director sea el editor (directora de cine, 46 años).

Imaginar mucho en el momento de escribir. Pensar en la distribución, en el desarrollo del proyecto. Adaptar el guion al presupuesto. Trabajar con guion técnico al filmar y que el director sea el editor final (guionista, 30 años).
Un buen director y su equipo pueden hacer con una buena historia algo grande. Todo depende de la historia y de la forma de trabajo. Nunca perder la pasión (realizador, 52 años).

Cuando se consulta respecto de cómo lograr calidad de las historias en el cine chileno, la mayoría de los encuestados (59\%) se inclina por la originalidad del guion o la búsqueda de modelos narrativos propios. Más atrás, en orden de preferencia quedan las alternativas la existencia de espectadores en el cine chileno (18\%) y la formación profesional del guionista o realizador $(14,8 \%)$.

Respecto de las fuentes de financiamiento más empleadas, empatan en número de preferencias los dineros que entrega el Estado a través del Fondo de Fomento Audiovisual y los fondos privados nacionales (recursos propios, banca, empresas, fundaciones $\mathrm{u}$ otros), ambos con 42,6\% de respuestas. Esto tiene gran significado, pues sigue siendo el financiamiento privado el que impulsa gran parte de los proyectos audiovisuales en este período. La tendencia al alza en el número de estrenos de películas chilenas en los últimos cinco años confirma, eso sí, el gran impacto que han tenido las políticas públicas en esta materia. Hay que aclarar que la carencia de estudios cualitativos sobre la estructura del relato le ha impedido a la industria ver la relación entre los modelos de guion de esas películas y los estándares profesionales de creación (Dittus, 2015a).

Futuras investigaciones podrían profundizar cualitativamente sobre las motivaciones de quienes escriben para cine. ¿Se escribe para ganar fondos o para cautivar a nuevas audiencias?, es la interrogante que queda en el aire. En la práctica, se reconoce que lo habitual es presentar a los concursos financiados por el Estado aquellos guiones que son modificados en el rodaje y que luego se siguen cambiando en el montaje. Esa realidad, sin embargo, es inherente al trabajo audiovisual y no parece ser un obstáculo para generar buenos resultados en taquilla o crítica. Dicho de otro modo, un guion cuidadosamente elaborado y defendido a rajatabla hasta el final en la sala de edición no garantiza una buena película.

En esa línea, el perfil de las audiencias es otro tema controversial, principalmente en lo que refiere al destinatario de la obra, y es la razón por la que muchos filmes estrenados en festivales no tienen la misma repercusión que en las salas comerciales de exhibición. Cuando se pregunta sobre el público destinatario, 41,7\% de los encuestados afirma que es el público masivo internacional, seguido por el público masivo 


\begin{tabular}{lccc}
\multicolumn{1}{c}{ Alternativa } & Número de respuestas & Porcentaje [\%] \\
\hline Espectadores interesados en ver cine chileno & 11 & 18 \\
\hline El presupuesto de la película & 3 & 4,9 \\
\hline La originalidad o búsqueda de modelos narrativos & 36 & 59 \\
\hline La formación profesional del guionista o realizador & 9 & 14,8 \\
\hline La alianza que se logre con realizadores extranjeros & 2 & 3,3 \\
\hline
\end{tabular}

Tabla 3: PREGUNTA 22. El valor otorgado a la calidad de las historias en el cine chileno depende, en gran medida, de:

Fuente: Elaboración propia.

\begin{tabular}{lcc}
\multicolumn{1}{c}{ Alternativa } & Número de respuestas & Porcentaje [\%] \\
\hline $\begin{array}{l}\text { El criterio del jurado de festivales no es necesariamente } \\
\text { comercial }\end{array}$ & 20 & 32,3 \\
\hline $\begin{array}{l}\text { El espectador chileno no sabe apreciar el buen cine } \\
\text { Ganar un festival no es sinónimo de calidad }\end{array}$ & 2 & 12,9 \\
\hline $\begin{array}{l}\text { cinematográfica } \\
\text { pos realizadores chilenos no hacen cine pensando en el }\end{array}$ & 8 & 27,4 \\
\hline $\begin{array}{l}\text { La narrativa del cine comercial norteamericano es } \\
\text { dominante }\end{array}$ & 17 & 24,2 \\
\hline
\end{tabular}

Tabla 4: PREGUNTA 23. A su juicio, ¿a qué se debe que existan películas chilenas premiadas en festivales internacionales que no tienen igual repercusión en las salas de exhibición?

Fuente: Elaboración propia.

nacional y un público más selecto de amantes del buen cine, ambas alternativas con $26,7 \%$ de las opciones. Porcentajes similares de respuestas reciben las opciones a la segunda pregunta, que busca entender la falta de apoyo del público chileno con el cine galardonado. Un 32,3\% de los encuestados indica que el criterio del jurado de festivales no es necesariamente comercial, $27,4 \%$ señala que los realizadores chilenos no hacen cine pensando en el gran público y $24,2 \%$ de las respuestas considera que la estructura narrativa del cine comercial norteamericano es dominante.

El apoyo al cine nacional es tema obligado cada vez que se abordan las dificultades que tienen los realizadores chilenos. Las opiniones expresadas, sin embargo, dan cuenta de un entusiasmo contagioso, pero lleno de crítica. "Los fondos del Estado benefician historias repetidas y comerciales", dice un encuestado (guionista, 33 años). La razón sería que "el cine norteamericano bobo controla las salas y el público parece disfrutarlo", señala el mismo consultado. "La única forma de sobrevivir-dice otro-es no descartando nunca la autogestión, inventar nuevas formas de financiamiento y la resistencia por sobre todas las cosas" (directora de cine, 42 años). En la misma línea argumental, otras opiniones señalan que "dado los ingratos números de audiencia que ha tenido históricamente el cine chileno, dejando de lado las escasas excepciones de éxito con el público, los autores han creado con la certeza de que el público masivo no los verá" (productor, 52 años). De este modo, pareciera que los discursos del cine chileno se han orientado hacia el único público al que pueden aspirar, generando un círculo vicioso en donde no queda claro 
si es poco visto por ser muy de nicho o es de nicho y por ello a los realizadores no les queda más remedio que responder a dichas expectativas.

Las siguientes expresiones apoyan la tesis indicada:

"Se debe pensar un proyecto cinematográfico que considere la opinión del público" (productora, 44 años).

"El público no es el mismo de hace 15 o 20 años (...) que el tópico de la dictadura cansa y que los mapuches no son hobbits" (crítico de cine, 31 años)

"No piensen en ser validados por festivales europeos, que intenten mostrar y vincularse con cineastas latinos más que pasear por alfombras rojas" (productor, 48 años)

"La búsqueda debería ser un equilibrio entre un cine que proponga reflexiones estéticas, pero a la vez satisfaga la necesidad de cultivar audiencias más amplias" (cineasta, 33 años)

"Hay que mirar más de cerca la realidad, dejar de pensar en los festivales de cine y en el glamour, o el estatus que otorgan" (profesora universitaria de cine, 55 años).

"No hacer una película pensando en los premios o en el número de espectadores que verá tu cinta. Más bien pensar en lo que se quiere decir, ser honesto, original y creativo" (guionista, 41 años).

Estas opiniones reflejan la necesidad de un camino propio. En el análisis de la evolución del cine chileno, su estado actual, sus fortalezas y debilidades, hay coincidencia en que no estamos ante una industria consolidada, sino más bien ante una práctica artesanal con muchas ganas y pocos recursos, de acuerdo a $41,9 \%$ de los entrevistados, y a una variada gama de corrientes artísticas, según $37,1 \%$. De hecho, hay elementos sustantivos en el relato fílmico, como el discurso autoral y la identificación de un conflicto, que son reconocidos como fortalezas con $45 \%$ y un 30\% de respuestas, respectivamente. En tanto, como debilidades del guion en el cine chileno actual figuran la construcción de la trama, con $43,3 \%$, y los diálogos, con 33,3\%. Para el grueso de los encuestados, todos los diálogos debieran tener una observación previa, interactuando con distintos personajes, en sus visitas a terreno y observando cuáles son sus dinámicas. El hecho de que son los personajes de carne y hueso los que inspiran la ficción fue reforzado permanentemente por algunos guionistas.

Esta visión sobre el cine chileno es complementada con otras dimensiones de la misma encuesta. La mayoría de los consultados señala que el principal objetivo que se busca en la realización de una película en Chile es representar una realidad social histórica o cotidiana
(53,3\%), seguido mucho más atrás por las opciones de entretener al público (16.7\%), obtener reconocimiento de los pares y de la crítica (13.3\%), y plantear un tema controversial a la sociedad (11,7\%). Dicha percepción es coherente con quienes piensan -la mayoría-que no existe temática que sea objeto de censura $(40,3 \%$ de las opiniones) en las etapas de financiamiento, difusión o exhibición del cine nacional. Entre las opciones que figuran como temáticas potencialmente censuradas están el poder (política, religión, negocios), con 24,2\% de las preferencias, y la sexualidad, con 19,4\% de las respuestas. Alternativas menos votadas son la marginalidad $(9,7 \%)$ y la dictadura militar (6,5\%). A juicio de un encuestado, debido a la similar procedencia social de quienes hacen cine, los tratamientos narrativos tienden a ser similares. "En Chile es muy poco recurrente que los guionistas se salgan de los esquemas, incluso en el cine más reflexivo. El cine que se produce en el país es endogámico, por eso la producción cinematográfica responde a lo mismo", enfatiza la misma fuente (director de cine, 31 años). En el análisis de las tramas efectuadas para este mismo estudio, la forma en la que se resuelven los conflictos es predecible. Se sigue la misma lógica en términos del bien y el mal y en la resolución de los problemas sexuales, económicos o políticos. La estrategia que asoma es la del "hazlo tú mismo", en la que producciones destacadas se hacen en pocos fines de semana y con una pequeña cámara digital, para contar historias personales, alejadas de la denuncia política, pero amparadas en el desamparo y la nostalgia, tal como ha sido constatado por otros estudios (Horta, 2013).

\section{CONCLUSIONES}

Los datos entregados en este análisis cuantitativo dibujan el perfil de la discreta profesión de ser guionista en Chile. Se trata de una sutil radiografía sobre quienes marcan el inicio de la cadena productiva de la realización audiovisual. En lo medular, son profesionales y técnicos que dedican gran tiempo a labores propias del relato, en cualquiera de las clásicas tareas del rubro: producción, dirección o escritura. En la práctica, todos ellos son coescritores. El guion como metodología permite comprender las aristas de una actividad que se nutre de una variedad de procedencias e irregulares horas de dedicación, expresadas en diversidad de formatos y soportes audiovisuales.

Las respuestas al cuestionario dejan en evidencia un conjunto de prácticas y formas de trabajar el guion 
en Chile que, lejos de cerrar el tema, lo abren y potencian. Los datos confirman la inexistencia de parámetros estables o principios dramatúrgicos que se apliquen como molde en el proceso de creación escritural (ya sea siguiendo a una escuela o inspirados en una corriente teórica propia o externa), advirtiendo, en cambio, la convivencia de diversos procesos creativos, ya sea en la generación de la idea dramática como en la composición de quienes participan en la confección del guion. En ese sentido, los guionistas y realizadores encuestados no reconocen sentirse parte de una tradición escritural. La ausencia de una formación sistemática en escritura creativa repercute en una descripción identitaria típicamente chilena, aun cuando se reconoce cierta adscripción a modelos narrativos foráneos o más clásicos, como el aristotélico. La escasa o mediana valoración que se tiene de los nombres propuestos en el cuestionario pone de manifiesto la poca adhesión filosófica a fórmulas probadas.

La injerencia de otro guionista, realizador o experto en la fase escritural es valorada en forma categórica, muy por encima de lo que pueda decir un investigador, un crítico de arte o a alguien desvinculado del área audiovisual. Este reconocimiento de los pares supone la importancia de la práctica en un área con escaso desarrollo teórico. Y es que el crecimiento del guion es fruto del trabajo en equipo. El recorrido de cada proyecto se ve enfrentado a las opiniones en un acto colaborativo en el que la última versión la propone mayoritariamente, el director y, en menor medida, los actores. En las respuestas se confirma la tesis de que el guion no permanece inmutable: no es la guía maestra del proceso de filmación ni tampoco un documento menor que sufre algunos cambios con base en las necesidades presupuestarias. Se bosqueja el guion como un mapa, y no un territorio. En él se reflejan la realidad matizada de los actores, las locaciones, los gastos de última hora o las diferencias que el director tiene con el productor. La filmación se presenta, entonces, como un bosque que el guionista no es capaz de prever con exactitud. Abraza todos aquellos cambios posibles con base en aportes artísticos de otros involucrados en el proceso de filmación. En este sentido, se reconoce la práctica del método recursivo, pero de modo colectivo. Las tensiones en torno a la autoría, la originalidad, la calidad de los diálogos o las temáticas de las que se narra no son temas relevantes. Tampoco lo es la dualidad de director-guionista. Un número importante de encuestados opina que ambos comparten autoría por la película, idea que es refrendada con la posibilidad de que el guionista y el director sean la misma persona.

Un tema siempre candente es el que valora la calidad de las historias del cine chileno. La ausencia de temáticas que, en forma categórica, sean percibidas como material censurable da cuenta de un Chile audiovisual que se mueve en mayores espacios de libertad. El que se identifique a la originalidad o la búsqueda de modelos narrativos propios como el valor otorgado a la calidad de las historias en el cine chileno supone el reconocimiento de que el buen cine no depende exclusivamente del financiamiento ni de una buena estrategia de marketing. Esto queda en evidencia una vez más, cuando se reconoce al discurso autoral como la gran fortaleza de nuestro cine. Se trata del deseo de narrar un punto de vista con riesgo, dedicación y honestidad. La contraparte es categórica. Las máximas expresiones del buen guion asoman como las debilidades dramatúrgicas del cine chileno: trama y diálogos. La incapacidad de ubicar esa bifurcación parece ser la deuda de aquellos que miden el impacto por las cifras. La falta de apoyo del público en las salas comerciales no se condice con la buena recepción de nuestras películas en los festivales. Es ese territorio desconocido el máximo desafío para la metodología de la creación audiovisual. La mayoría de los encuestados manifiestan sus formas de proceder en esta materia desde lógicas y filosofías opuestas pero que, en el fondo, no tienen por qué anularse.

La actividad escritural se acerca velozmente a la lógica de una industria cada vez más exigente y competitiva, donde la televisión ya ha dado claras muestras de profesionalismo. El cine contemporáneo -en su justa diversidad- exige nuevas formas de contar historias y equipos de guionistas, en una sociedad en la cual el cambio radical ya no son las nuevas tecnologías sino la participación que las audiencias tienen en ella. Siguiendo a Scolari (2013), la escritura de un guion dejó de ser responsabilidad de una única persona. Bajo esta premisa es posible aventurar nuevas preguntas de investigación dirigidas a un modelo de negocio que llegó para quedarse, en el que lo que sirvió alguna vez para el cine y la televisión hoy es parte de otras estrategias audiovisuales. En suma, hablamos de la expansión del universo narrativo, donde cada medio -incluido el cine- puede llegar a ser un fragmento que aporta, con lo mejor de sí mismo, a la historia en esa experiencia multiplataforma. 
NOTA

Este trabajo presenta parte de los resultados del Proyecto FONDECYT N¹1130680, titulado Modelos de guion en el cine chileno de ficción. Asimismo, constituye el fundamento teórico del Proyecto FONDECYT N¹160637, titulado La formación del guionista en Chile, ambos financiados por la Comisión Nacional de Desarrollo Científico y Tecnológico de Chile (CONICYT).

\section{REFERENCIAS}

Aristóteles (2003). Poética [Poetics]. Buenos Aires: Losada.

Basulto, O. (2016). El oficio de script doctor en Chile: iniciación al estudio de la evaluación de guiones en cine y televisión [The office of doctor script in Chile: initiation to the study of the evaluation of scripts in film and televisión]. In INCOM Chile, Asociación Chilena de Investigadores en Comunicación (Ed.), Creatividad e innovación para investigar la comunicación (Enfoques, Problemáticas \& Metodologías) [Creativity and innovation to investigate communication (Approaches, Issues and Methodologies)] (pp. 446-448). Retrieved from http://45.55.160.4/wp-content/uploads/2012/03/Actas2016.pdf

Bolzoni, F. (1974). El cine de Allende [The cinema of Allende]. Valencia: Fernando Torres Editor.

Brenes, C. S. (2011). El valor práctico de la teoría: Enseñar la Poética de Aristóteles a guionistas [The Practical Value of Theory: Teaching Aristotle's Poetics to Screenwriters]. Comunicación y Sociedad, 24(1), 101-117. Retrieved from http://dadun.unav.edu/bitstream/10171/23807/1/BRENES.pdf

Brenes, C. S. (2014). La Poética de Aristóteles en los manuales de guion: valoración crítica [Quoting and Misquoting Aristotle's Poetics in Recent Screenwriting Bibliography]. Comunicación y Sociedad, 27(2), 55-78. Retrieved from https://dadun.unav.edu/handle/10171/36272

Briceño, F. (2015). La marginalidad urbana representada en el cine latinoamericano posglobalización [The urban marginality represented in post-globalization Latin American cinema]. In M. Villarroel (Ed.), Nuevas travesías por el cine chileno latinoamericano [New Journeys for Chilean and Latin American Cinema] (pp. 29-39). Santiago: LOM.

Cano, P. (1999). De Aristóteles a Woody Allen [From Aristotle to Woody Allen]. Barcelona: Gedisa

Dittus, R. (2017) ¿Guionistas o directores? El dilema en el fomento del cine chileno [Scriptwriters or directors? The dilemma in the promotion of Chilean cinema]. In M. Ramos (Ed.), Historia, literatura $y$ arte en el cine en español y portugués: estudios y perspectivas [History, literature and art in Spanish and Portuguese cinema: studies and perspectives] (pp. 945-959). Salamanca: Centro de Estudios Brasileños.

Dittus, R. (2016). El personaje brechtiano en el novísimo cine chileno: análisis de los filmes Gatos viejos Lucía y el Cielo, la tierra y la lluvia [The Brechtian character in the latest Chilean cinema: analysis of the films Gatos viejos, Lucía y el Cielo, la tierra y la lluvia]. Perspectivas de la Comunicación, 9(2). 59-70. Retrieved from http://publicacionescienciassociales.ufro.cl/index.php/perspectivas/article/view/657

Dittus, R. (2015a). Fundamentos para un estudio del guion en el cine chileno: notas preliminares [A Theoretical Frame for a Study of the Script in the Chilean Cinema: Preliminary Notes]. Aisthesis, (58), 237-254. Retrieved from https://doi.org/10.4067/S0718-71812015000200012

Dittus, R. (2015b, October). Modelos de guion en el cine chileno: entre la dramaturgia oculta y el discurso autoral [Models of script in the Chilean cinema: between the hidden dramaturgy and the authorial discourse]. Lecture presented at IX Congreso Internacional Chileno de Semiótica, Pucón, Chile.

Field, S. (1995). El manual del guionista [The Screenwriter's Workbook]. Madrid: Plot.

Fuenzalida, V., Corro, P., \& Mujica, C. (2009). Melodrama, Subjetividad e Historia en el cine y televisión chilenos de los 90 [Melodrama, Subjectivity and History in the Chilean cinema and television of the 90's]. Santiago: Publicación propia, Fondo de Fomento Audiovisual. 
Gournay, B. (2004). Contra Hollywood: estrategias europeas del mercado cinematográfico y audiovisual [Against Hollywood: European strategies for the film market and world]. Barcelona: Ediciones Bellaterra.

Horta, L. (2013). ¿Por qué filmamos lo que filmamos? Diálogos en torno al cine chileno 1990-2010 [Why do we film what we shoot? Dialogues around the Chilean cinema 1990-2010]. Santiago de Chile: Cuarto Propio.

Lübbert, O. (2009). Guion para un cine posible [Screenplay for a possible cinema]. Santiago de Chile: Uqbar.

McKee, R. (2002). El Guion [Story]. Barcelona: Alba.

Robino, A. (2015). Manual de análisis de estructura dramática [Dramatic Structure Analysis Manual]. Santiago de Chile: Universidad Finis Terrae.

Ruffinelli, J. (2007). El cine nómada de Cristián Sánchez [The nomadic cinema of Cristián Sánchez]. Santiago de Chile: Uqbar.

Ruiz, R. (2013). Poéticas del cine [Poetics of the cinema]. Santiago: Ediciones Universidad Diego Portales

Pérez, J. A. (2004). Teatro y cine: un permanente diálogo intermedial [Theater and cinema: a permanent intermedial dialogue]. Arbor, 177(699/700), 573-594. https://doi.org/10.3989/arbor.2004.1699/700.596

Póo, X., Stange, H., \& Salinas, C. (2012). Políticas de la subjetividad en el novísimo cine chileno [Politics of subjectivity in the new Chilean cinema]. Comunicación y Medios, (26), 5-11. Retrieved from http://www.comunicacionymedios.uchile.cl/index.php/RCM/article/download/25580/27992

Sánchez, C. (2011). Aventura del cuerpo. El pensamiento cinematográfico de Raúl Ruiz [Adventure of the body. The cinematographic thought of Raúl Ruiz]. Santiago de Chile: Ocho Libros.

Sánchez-Escalonilla, A. (2001). Estrategias de guion cinematográfico [Strategies of cinematographic script]. Barcelona: Ariel.

Sanz-Magallón, A. (2007). Cuéntalo bien. El sentido común aplicado a las historias [Narrate it well. Common sense applied to stories]. Madrid: Plot.

Seger, L. (2011). Cómo convertir un buen guion en un guion excelente [How to Convert a Good Screenplay into an Excellent Screenplay]. Madrid: Rialp.

Scolari, C. (2013). Narrativas transmedia: cuando todos los medios cuentan [Transmedia narratives: when all the media count]. Barcelona: Deusto.

Snyder, B. (2010) ¡Salva al gato! [Save the Cat!]. Barcelona: Alba.

Stranger, I. (2001). Cuadernos de dramaturgia [Notebooks of dramaturgy]. Santiago: Frontera Sur.

Trejo, C. (2014). Cambios culturales, imaginarios colectivos y cine chileno actual [Cultural changes, collective imaginaries and current Chilean cinema]. In C. Barril, P. Corro, \& J. M. Santa Cruz (Eds.), Audiovisual y Política en Chile [Audiovisual and Politics in Chile] (pp. 15-28). Santiago de Chile: Editorial Arcis.

Tubau, D. (2011). El guion del siglo 21 [The 21st century script]. Barcelona: Alba.

Urrutia, C. (2013). Un cine centrífugo, ficciones chilenas 2005-2010 [A centrifugal cinema, Chilean fiction 2005-2010]. Santiago de Chile: Cuarto Propio.

Vergara, X. (2015). Ficciones en el cine chileno universitario: el caso de la Escuela de Artes de la Comunicación UC (1968-1978) [Fictions in the Chilean university cinema: the case of the School of Arts of Communication UC (1968-1978)]. In M. Villarroel (Ed.), Nuevas travesías por el cine chileno y latinoamericano [New Journeys for Chilean and Latin American Cinema] (pp. 117-127). Santiago de Chile: LOM.

Vogler, C. (2002). El viaje del escritor [The Writer's Journey: Mythic Structure For Writers]. Barcelona: Manontroppo. 
Rubén Dittus, profesor investigador de la Facultad de Comunicaciones de la Universidad Central de Chile. Doctor en Ciencias de la Comunicación por la Universidad Autónoma de Barcelona, Magíster en Guion Cinematográfico por la Universidad Finis Terrae y Periodista por la Universidad Católica de la Santísima Concepción. Ha dirigido proyectos en el área de la narrativa audiovisual, financiados por el Fondo Nacional de Desarrollo Científico y Tecnológico. Es editor de la Revista Chilena de Semiótica y director del núcleo de investigación "guionchile.cl". 